\title{
Correlation between Structure Characteristics and Pair Radial Distribution Function in Silica Glass under Compression
}

\author{
Mai Thi Lan*, Tran Thu Thuy, Le Thi Hong Lien, Le Van Vinh \\ Hanoi University of Science and Technology \\ Received 28 November 2018 \\ Revised 25 December 2018; Accepted 26 December 2018
}

\begin{abstract}
We have studied structure of silica glass at different pressures and temperature of $300 \mathrm{~K}$ by using Molecular Dynamics simulation (MD) method. The model consists of 6000 atoms (2000 $\mathrm{Si}, 4000 \mathrm{O}$ atoms) with the periodic boundary condition. We applied the Morse-Stretch potentials which describe the pairwise interactions between ions for $\mathrm{SiO}_{2}$ system. There is structural phase transformation from tetrahedra $\left(\mathrm{SiO}_{4}\right)$ to octahedra $\left(\mathrm{SiO}_{6}\right)$ network structure. There is splitting in the $\mathrm{Si}$-Si pair radial distribution function (PRDF) at high pressure (100 GPa). The original of this splitting relates to the edge- and face-sharing bonds. The new second peak of the O-O PRDF at the high pressure originates from oxygen atoms of the edge-sharing bonds. Thus, there is rearrangement of $\mathrm{O}$ atoms. $\mathrm{O}$ atoms have tendency to more order arrangement that leads to form some oxygen hcp and fcc structure in the model at high pressure.
\end{abstract}

Keywords: Molecular Dynamics simulation (MD), Silica (SiO2), Structure, the peak splitting.

\section{Introduction}

Silica $\left(\mathrm{SiO}_{2}\right)$ is one of the most intensively investigated materials due to its importance in high technology materials (ceramic, semiconductor, solar cell) and geophysical sciences. $\mathrm{SiO}_{2}$ is typical network-forming oxide that studied for a long time by both experiments (X-ray diffraction, neutron diffraction, nuclear magnetic resonance, ...) and simulations. These studies have shown that under different temperature and pressure conditions, the change of network structure have a great influence on the physical properties of the $\mathrm{SiO}_{2}$ material. Zachariasen [1] predicted that the structure of $\mathrm{SiO}_{2}$ in amorphous and liquid state comprised mainly by $\mathrm{SiO}_{4}$ basic structural units that are linked together to form network structure at different temperature. This prediction is confirmed by Mozzi and Warren through X-ray diffraction [2]. The short- range order structure are determined by calculation of the coordination number, the radial distribution function of the $\mathrm{Si}-\mathrm{Si}, \mathrm{Si}-\mathrm{O}$ and $\mathrm{O}-\mathrm{O}$ pairs, distribution of

\footnotetext{
*Corresponding author. Tel.: 84-988277387.

Email: lan.maithi@hust.edu.vn

https//doi.org/ 10.25073/2588-1124/vnumap.4304
} 
the O-Si-O and Si-O- $\mathrm{Si}$ bond angles in $\mathrm{SiO}_{x}$ units. The $\mathrm{Si}-\mathrm{O}-\mathrm{Si}$ bond angle in the $\mathrm{SiO}_{2}$ glass is about $144^{\circ}$. The result of the high-energy X-ray diffraction for amorphous $\mathrm{SiO}_{2}$ presented the Si-O-Si bond angle is $147^{\circ}$. By the ${ }^{17} \mathrm{O}$ NMR spectrum analysis of $\mathrm{SiO}_{2}$ glass, the mean $\mathrm{Si}-\mathrm{O}-\mathrm{Si}$ bond angle is $144^{\circ}$ [1]. By using MD simulation, network structure of $\mathrm{SiO}_{2}$ is built from basic structural units $\mathrm{SiO}_{4}$ at low pressure. Under compression, there is transformation from $\mathrm{SiO}_{4}$ structure to $\mathrm{SiO}_{6}$ structure via $\mathrm{SiO}_{5}$ unit. At high pressure, structure of $\mathrm{SiO}_{2}$ is a mixture of $\mathrm{SiO}_{\mathrm{x}}(\mathrm{x}=4,5,6)$ units [3-5]. At all temperature and ambient pressure, structure of $\mathrm{SiO}_{2}$ is mainly $\mathrm{SiO}_{4}$ units that form tetrahedra network. The fraction of $\mathrm{SiO}_{5}$ is very negligible. Thus, $\mathrm{SiO}_{5}$ units are the same as structural defects in $\mathrm{SiO}_{2}$ [6-8]. The properties of silica depend on the change of fraction of $\mathrm{SiO}_{\mathrm{x}}$ units as well as the type of linkages and the spatial distribution of $\mathrm{SiO}_{x}$ units. Therefore, the studying of structure of $\mathrm{SiO}_{2}$ at different temperature and pressure conditions is necessary. In this paper, we use MD simulation and visualization of MD data to investigate $\mathrm{SiO}_{2}$ system. The aim of this work is to clarify the correlation between structure characteristics and pair radial distribution function, explain the splitting of Si-Si PRDF and the second peak of O-O PRDF in Silica glass under compression.

\section{Calculation method}

We used MD simulation method and employed the Morse-Stretch potential to construct MD models for $\mathrm{SiO}_{2}$. Details about potential parameters can be found in reference [9]. The MD initial configuration is generated by randomly placing 6000 atoms $(2000 \mathrm{Si}, 4000 \mathrm{O}$ atoms) in cubic box $(44.65 \times 44.65 \times 44.65$ $\AA$ ) with periodic boundary condition. To remove the effect of remembering initial configuration, the sample is heated up to $6000 \mathrm{~K}$ and relaxed after $2.10^{4} \mathrm{MD}$ steps to reach the equilibrium. Then, the sample was cooled down to the designed temperature and pressure $(300 \mathrm{~K}$ and $0 \mathrm{GPa}$, denoted M1 model) and relaxed in a long time. After that, the models at different pressures $(0,30$ and $100 \mathrm{GPa})$ were constructed by compressing M1 model. Next, these models were relaxed for $10^{6}$ MD steps in NPT ensemble to reach the best equilibrium. The structural characteristics of considered models are determined by averaging over 1000 configuration during the last $2.10^{4} \mathrm{MD}$ steps.

\section{Result and discussion}

The result of pair radial distribution functions is given in figure 1. The result is consistent with previous simulations and experimental data [10-15]. For Si-O pair, the position of the first peak at 1.60 $\AA$. Under compression, the first peak shifts to the right at $1.68 \AA$. Conversely, the first peak of $\mathrm{Si}-\mathrm{Si}$ and $\mathrm{O}-\mathrm{O}$ pair shift to the left under compression. It means that the bond length of $\mathrm{Si}-\mathrm{O}$ is longer, the bond length of $\mathrm{Si}-\mathrm{Si}$ and $\mathrm{O}-\mathrm{O}$ is shorter. These is explained by the transformation from $\mathrm{SiO} 4$ units to $\mathrm{SiO} 6$ units via $\mathrm{SiO} 5$ units (figure 2). Note that, there is splitting of the first peak of Si-Si PRDF (located at r1 $=2.70$ and $\mathrm{r} 2=3.10 \AA$ ) and appearance the new second peak of the O-O PRDF (located at $3.4 \AA$ ). The cause of these interesting results will be more analyzed and clarified in the following section. The figure 2 showed the dependence of coordination number on pressures. It showed that, at low pressure, the structure of $\mathrm{SiO} 2$ is comprised mainly by $\mathrm{SiO} 4$ basic structural units ( $\mathrm{SiO} 4$ means that $\mathrm{Si}$ atom is surrounded by four $\mathrm{O}$ atoms at the nearest-neighbor distance). The fraction of $\mathrm{SiO} 4$ units is $99 \%$ but the fraction of $\mathrm{SiO} 5$ and $\mathrm{SiO} 6$ units is negligible. As increasing pressure, the fraction of $\mathrm{SiO} 4$ decrease strongly, the fraction of $\mathrm{SiO} 6$ units increases. At high pressure, the structure of $\mathrm{SiO} 2$ is comprised mainly by $\mathrm{SiO} 6$ units. Thus, there is structural phase transformation from $\mathrm{SiO} 4$ tetrahedra to $\mathrm{SiO} 6$ octahedra network under compression. The $\mathrm{SiOx}(\mathrm{x}=4,5,6)$ basic structural units are linked each other by common oxygens to form continuous random network in three-dimensional space. 
The network structure of $\mathrm{SiO}_{2}$ glass at different pressures is visualized in figure 3. We found that, the $\mathrm{SiO}_{\mathrm{x}}$ units are connected each other by sharing one, two or three oxygens and these ones corresponding to the corner-, edge- or face-sharing bonds. The bond statistics corner-, edge- and facesharing bonds between two adjacent $\mathrm{SiO}_{\mathrm{x}}$ units are showed in table 1 .

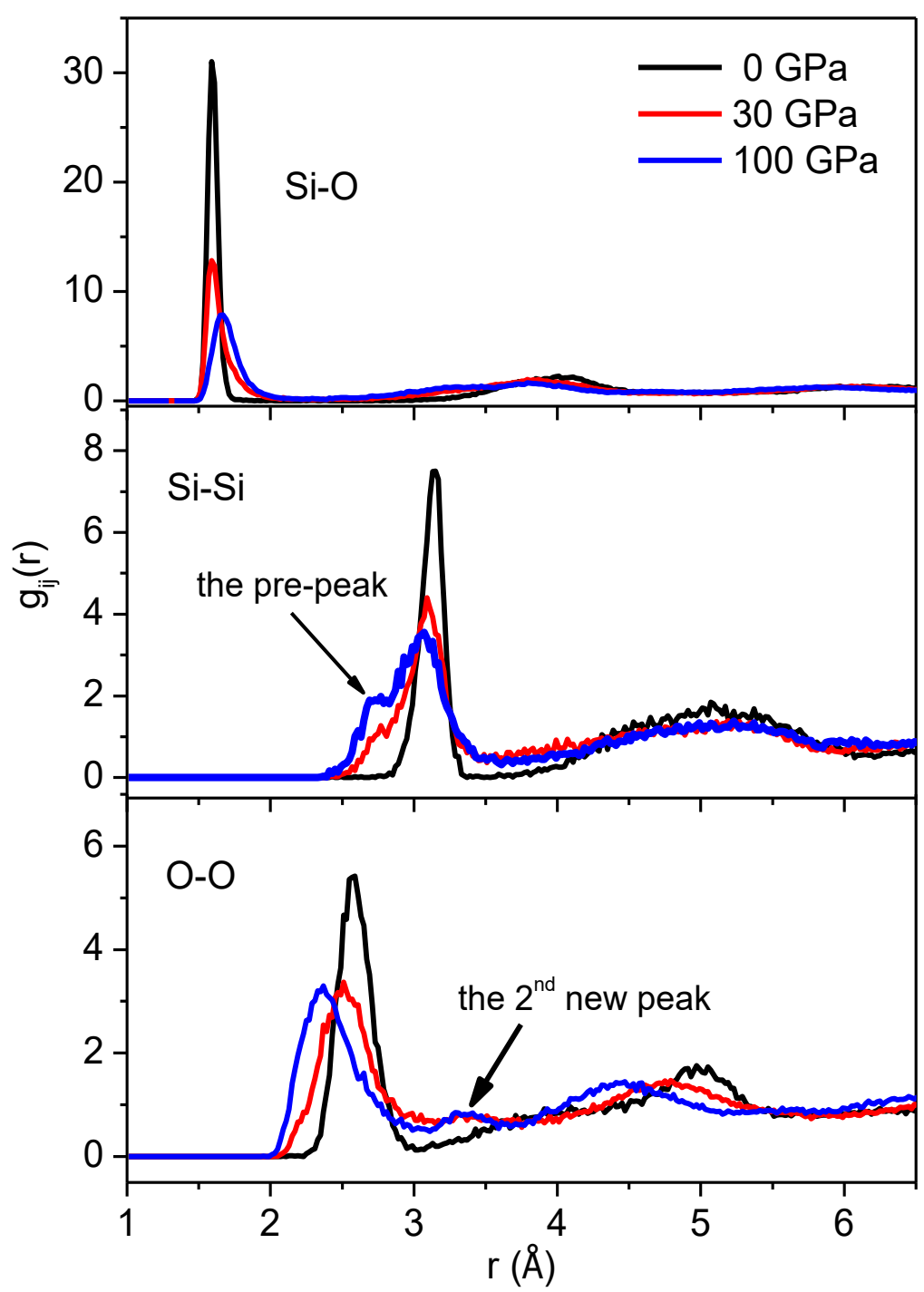

Figure 1. The dependence of the pair radial distribution functions of $\mathrm{SiO}_{2}$ glass on pressures

Table 1. The number of oxygen corner-sharing $\left(\mathrm{N}_{\mathrm{c}}\right)$, edge-sharing $\left(\mathrm{N}_{\mathrm{e}}\right)$ and face-sharing $\left(\mathrm{N}_{\mathrm{f}}\right)$ atoms in $\mathrm{SiO}_{2}$ system.

\begin{tabular}{llll}
\hline $\mathrm{P}(\mathrm{GPa})$ & 0 & 30 & 100 \\
\hline $\mathrm{N}_{\mathrm{c}}(\%)$ & 99.65 & 66.67 & 17.20 \\
$\mathrm{~N}_{\mathrm{e}}(\%)$ & 00.35 & 30.85 & 70.85 \\
$\mathrm{~N}_{\mathrm{f}}(\%)$ & 00.00 & 02.48 & 11.95 \\
\hline
\end{tabular}




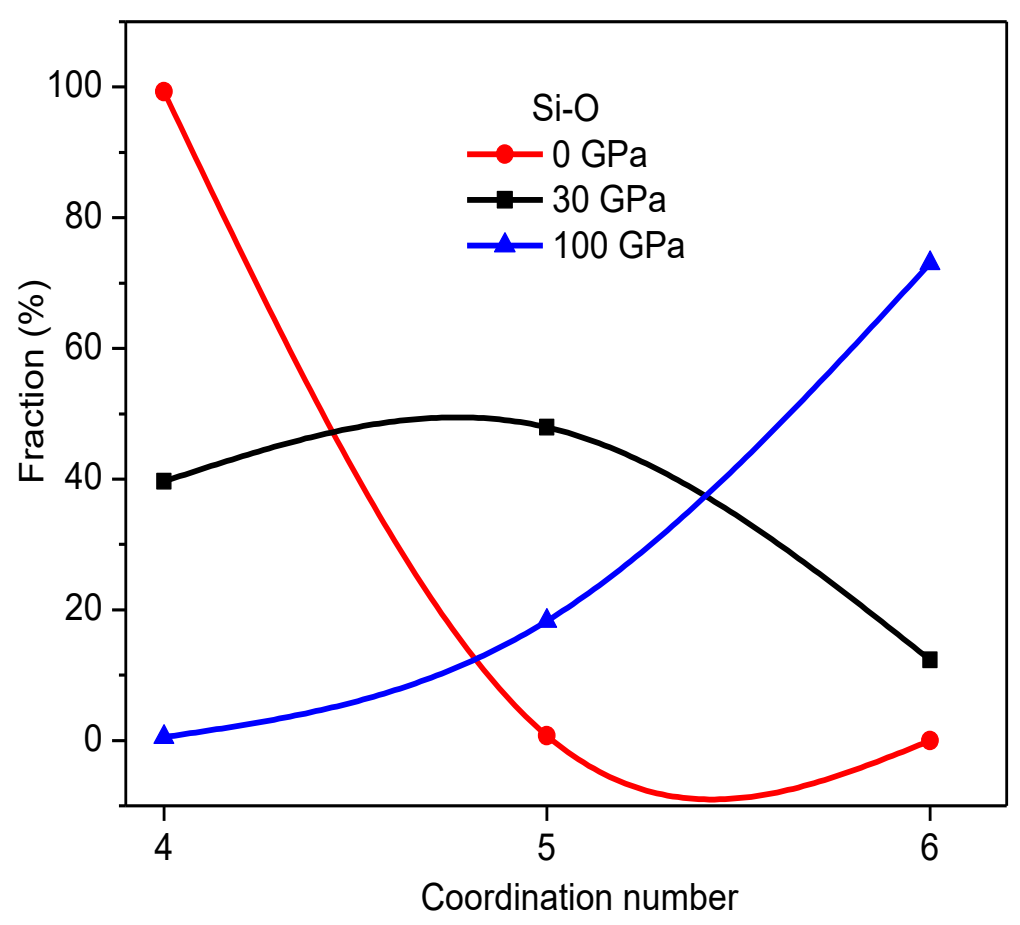

Figure 2. The dependence of coordination number on pressures.

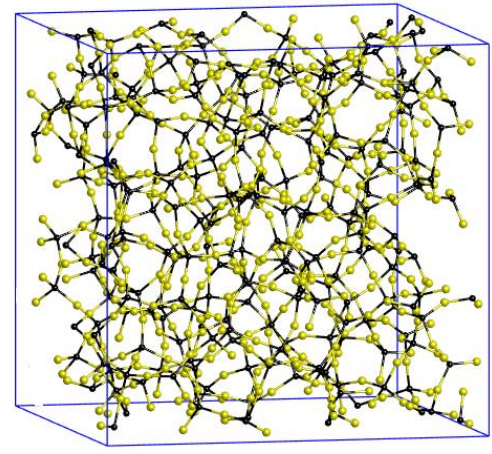

a) $0 \mathrm{GPa}$

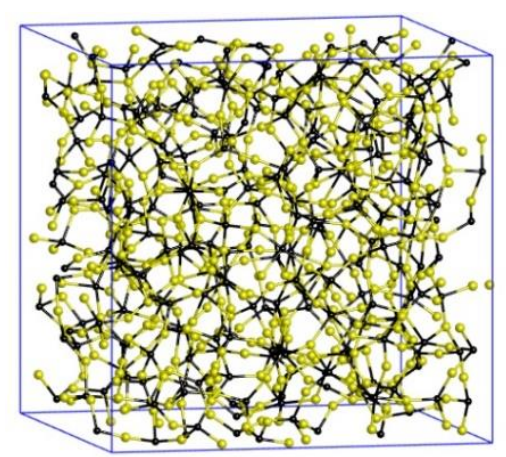

a) $30 \mathrm{GPa}$

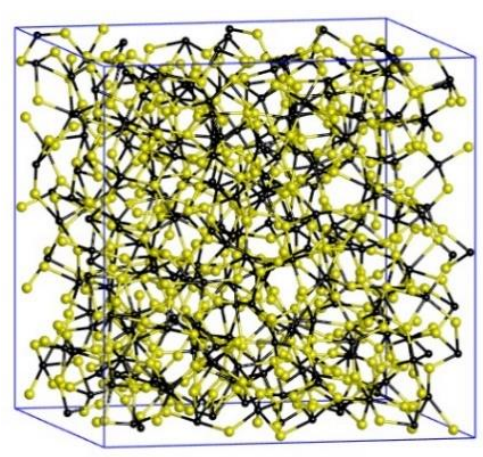

c) $100 \mathrm{GPa}$

Figure 3. The network structure of $\mathrm{SiO}_{2}$ glass at different pressures.

The result shows that at $0 \mathrm{GPa}$, links between two adjacent $\mathrm{SiO}_{\mathrm{x}}$ units are mainly corner-sharing bonds $(99.65 \%)$. When pressure increases, the fraction of corner-sharing bonds decreases, the fraction of edge- and face-sharing bonds increases. At high pressure, links between two adjacent $\mathrm{SiO}_{\mathrm{x}}$ units are mainly the fraction of edge-sharing bonds. As above mentioned, the structure of $\mathrm{SiO}_{2}$ is mainly build by $\mathrm{SiO}_{4}$ tetrahedra units at $0 \mathrm{GPa}$ and $\mathrm{SiO}_{6}$ octahedra units at $100 \mathrm{GPa}$. It means that links between two 
adjacent $\mathrm{SiO}_{4}$ units are mainly corner-sharing bonds, meanwhile links between two adjacent $\mathrm{SiO}_{5}, \mathrm{SiO}_{6}$ units are mainly edge-, face- sharing. Thus, the first peak splitting in the Si-Si PRDF at $r_{l}=2.70$ and $r_{2}$ $=3.10 \AA$ at $100 \mathrm{GPa}$ relates to the edge-, face-sharing bonds. Next, we focus on explaining the origin of appearance of the second new peak in O-O PRDF at $100 \mathrm{GPa}$. We calculated and analyzed the O-O PRDF of oxygen corner-, edge- and face-sharing atoms. This result is presented in figure 4.

For the O-O PRDF of oxygen corner- and face-sharing atoms, they have only single peak that located at about $2.50 \AA$ and $2.26 \AA$, respectively. However, the new second peak is observed in the O-O PRDF of oxygen edge-sharing atoms. This demonstrated that oxygen edge-sharing atoms cause the second peak of the O-O PRDF located at $3.40 \AA$. Moreover, we found that, with further increasing pressure, both of $\mathrm{Si}$ and $\mathrm{O}$ sublattices have a slight change. Meanwhile Si sublattice is more easily compressed than $\mathrm{O}$ sublattice at high pressure. $\mathrm{O}$ atoms have tendency to more order arrangement that leads to form some hexagonal close-packed (hcp) and faced centered cubic (fcc) structure of oxygen atoms in the model at high pressure. This result is visualized in figure 5 .

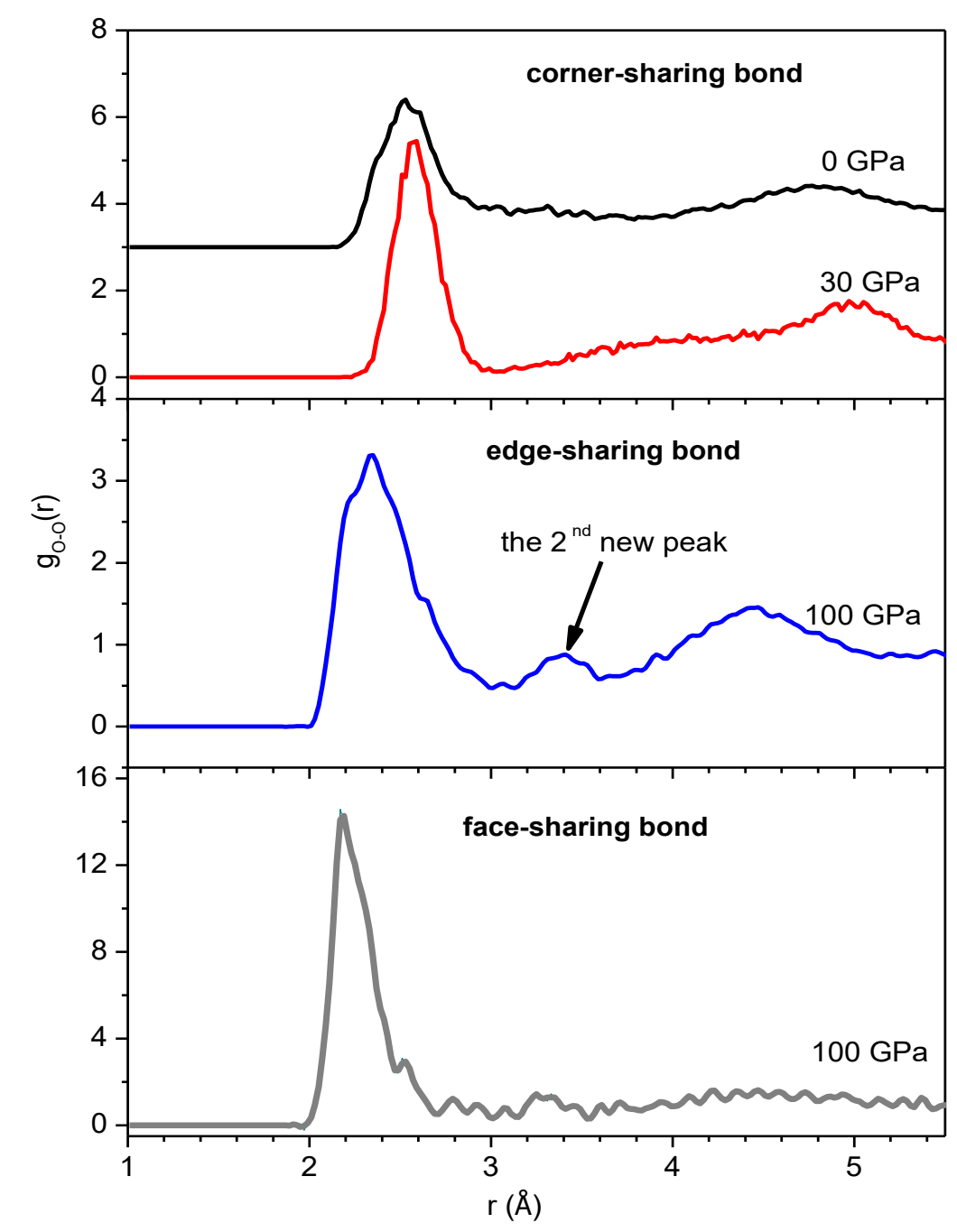

Figure 4. The O-O pair radial distribution functions of oxygen corner-, edge- and face-sharing atoms. 


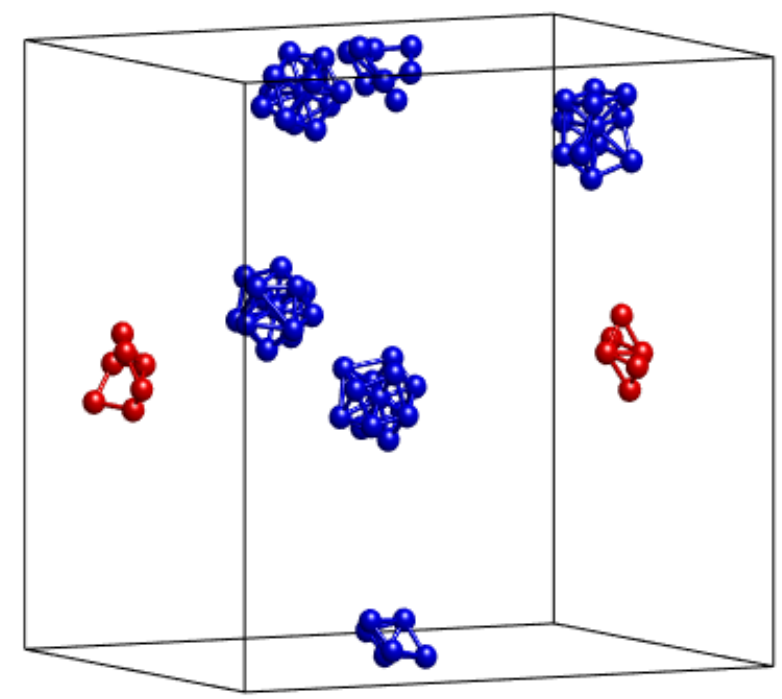

Figure 5. The fcc $\mathrm{O}$ atoms in blue color and hcp $\mathrm{O}$ atoms in red color at $100 \mathrm{GPa}$.

\section{Conclusion}

In this paper, we have obtained the main results as following:

(i) The structure of $\mathrm{SiO}_{2}$ is built by $\mathrm{SiO}_{\mathrm{x}}(\mathrm{x}=4,5,6)$ basic structural units, meanwhile, the structure of $\mathrm{SiO}_{2}$ is comprised mainly by $\mathrm{SiO}_{4}$ units at low pressure and $\mathrm{SiO}_{6}$ units at high pressure. There is structural phase transformation from tetrahedra $\left(\mathrm{SiO}_{4}\right)$ to octahedra $\left(\mathrm{SiO}_{6}\right)$ network structure via $\mathrm{SiO}_{5}$ units.

(ii) $\mathrm{The}^{\mathrm{SiO}_{\mathrm{x}}}$ units are connected each other by the corner-, edge- and/or face-sharing bonds.

(iii) The splitting in the Si-Si PRDF at high pressure due to the edge- and face-sharing bonds and oxygen edge-sharing atoms cause the second peak of the O-O PRDF.

(vi) Under compression, $\mathrm{O}$ atoms have tendency to more order arrangement that leads to form some hcp and fcc structure of $\mathrm{O}$ atoms in the model at high pressure.

\section{Acknowledgements}

This research is funded by the Vietnamese Ministry of Education and Training project (B2018BKA-57)

\section{References}

[1] W. Zachariasen, J. Am. Chem. Soc. 54, pp. 3841-3851(1932)

[2] Mozzi và Warren, J. App. Cryst. 2, pp. 164-172 (1969)

[3] Jin W, Kalia RK, Vashishta P, Phys Rev B. 50:118-131 (1994)

[4] Sato T, Funamori N. Phys Rev B. 82, 184102 (2010)

[5] Trachenko K, Dove MT. J Phys Condens Matter. 14:7449-7459 (2002) 
[6] Inamura Y, Katayama Y, Utsumi W, Phys Rev Lett. 93, 015501 (2004).

[7] P. K. Hung, N. V. Hong, and L. T. Vinh, J. Phys.: Condens. Matter 19, 466103 (2007).

[8] Vollmayr-Lee K, Zippelius A, Phys Rev E. 88:052145 (2013)

[9] P. Tangney and S. Scandolo, .J. Chem. Phys.117, 8898 (2002).

[10] P. K. Hung, N. V. Hong, and L. T. Vinh, J. Phys.: Condens. Matter 19, 466103 (2007).

[11] A. Zeidler, K. Wezka, R. F. Rowlands, D. A. J. Whittaker, P. S. Salmon, A. Polidori, J. W. E. Drewitt, S. Klotz, H. E. Fischer, M. C. Wilding, C. L. Bull, M. G. Tucker and M. Wilson, Phys. Rev. Lett. 113, 135501 (2014).

[12] L. I. Tatarinova, in The Structure of Solid Amorphous and Liquid Substances (Nauka, Moscow, 1983).

[13] M. Guerette, M. R. Ackerson, J. Thomas, F. Yuan, E. B. Watson, D. Walker and L. Huang, Sci. Rep. 5, 15343 (2015).

[14] W. Jin, R. K. Kalia, and P. Vashishta, Phys. Rev. B 50, 118 (1994).

[15] J. S. Tse, D. D. Klug, Y. L. Page, Phys. Rev. B 46, 5933 (1992). 